\title{
A Speed PMSM Control Technique With a Single DC Bus current Sensor
}

\author{
Mokrane BALA $^{1}$, Imen BAHRI ${ }^{1}$, Adrien MERCIER ${ }^{1}$, Mohamed KHANCHOUL ${ }^{2}$, Guillaume KREBS ${ }^{1}$ \\ ${ }^{I}$ GeePs $\mid$ Group of electrical engineering - Paris, CNRS, CentraleSupélec, Univ. Paris-Sud, Univ. Paris-Saclay,Sorbonne Univ. \\ Gif-sur-Yvette, France \\ ${ }^{2}$ Valeo Thermal Systems, La verrière, France \\ (Mokrane.bala, imen.bahri, adrien.mercier, guillaume.krebs)@geeps.centralesupelec.fr
}

\begin{abstract}
In this paper, we propose a speed Permanent Magnetic Synchronous Machine (PMSM) sensorless control technique. The approach is based on the measurement of the DC Bus current. A reconstruction phase current algorithm is developed and presented. This algorithm is mainly based on the switches' control signals of the inverter generated by the SVPWM. However the phase current reconstruction with a standard SVPWM induces some dead zones. So, the measurement of the DC Bus current is not possible due to the fact that the duration time of the active voltage vector is shorter than the minimum time necessary for the current acquisition. To overcome this issue, we propose an Adjusted SVPWM control strategy which allows a reliable reconstruction of the phases currents.
\end{abstract}

Keywords- PMSM, Sensorless current, reconstruction current phase algorithm, SVPWM.

\section{INTRODUCTION}

The Permanent Magnet Synchronous Machines (PMSM) are widely used in high speed applications. They are used in different fields due to a series of advantages. Their strengths are high power density, high efficiency and small torque ripple. Furthermore, their simple structure and small volume give them a great advantage and a wide range of application [1]-[2]. Different methodologies are used in the literature to control PMSMs [3]. In order to achieve a high-precision control performances of PMSM, accurate acquisition of phase current and position is needed. Usually, those information are obtained via current and position sensors. This comes at the expense of an increased cost and volume. Moreover, the control quality may be deteriorated due to inaccurate acquisition especially in noisy environment. Therefore, the best way to deal with those problems is to reduce the number of sensors used in the feedback loop and use sensorless control techniques.

Many current sensorless control techniques have been developed and are available in the literature [4]-[8]. The main idea of these techniques is the reconstruction of the phase currents based on the combination of the measurement of the DC Bus current and the switches control signals generated by the SVPWM. But, the drawback of such techniques are the dead zones where the DC Bus current acquisition is not possible. Several studies have reported this limitation and proposed some promising solution to bypass them [9]-[13]. However, all these papers propose a simulation or experimental tests at limited speed range around $1000 \mathrm{rpm}$ or $2000 \mathrm{rpm}$. Realising that to validate the reliability of the technique, it should be used in different operating point especially at high speed where the acquisition point are not enough.

This paper proposes a high speed PMSM sensorless control technique with a single current sensor. The phase currents are reconstructed using the measurement of the DC Bus current and via a phase current reconstruction algorithm. The main idea is to propose an Adjusted ASVPWM in order to ensure the minimum duration time of the active voltage vector which overcome the issue of dead zones and allow a proper reconstruction of the phase's currents. To validate the reliability of this technique and see its limits, a simulation test is carried out at different level of speed especially at high speed and with different switching frequency.

This paper is organized as follows: an overview of the system structure is depicted in section II. Section III addresses the current phase reconstruction algorithm. Simulation results and analysis are shown in Section IV. Lastly, section V draws some concluding remarks.

\section{SYSTEM STRUCTURE}

\section{A. overview}

Fig. 2 shows the typical block diagram of speed control of the PMSM, fed by a three phase bridge converter. The originality of this system is the use of a single current sensor.

The software of this system is composed of a reconstruction block of phase's currents, two control loop: current and speed, and the ASVPWM.

In this paper, we focus on the phase current reconstruction block and the ASVPWM block. The first block has as input the DC Bus current and the switch control signals which are generated by the ASVPWM, and it has as output the three phase currents. The second generates the switches control signals in order to command the inverter.

\section{B. Voltage source inverter}

A voltage source inverter is commonly used to supply a three phase induction motor with variable switching frequency and variable voltage for variable speed applications. The three phase inverter consists of six power switches and six freewheeling diodes as shown in "Fig. 1". Regarding the fact that the state of the two switches of the same arm are complementary, we can consider just the high level switches.

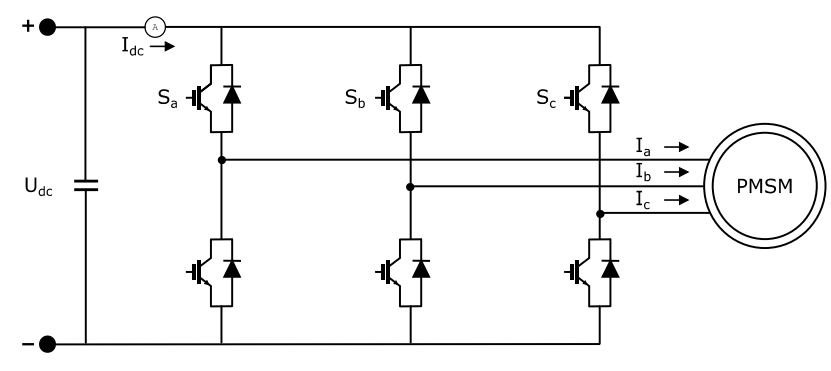

Fig. 1. Three phase inverter 


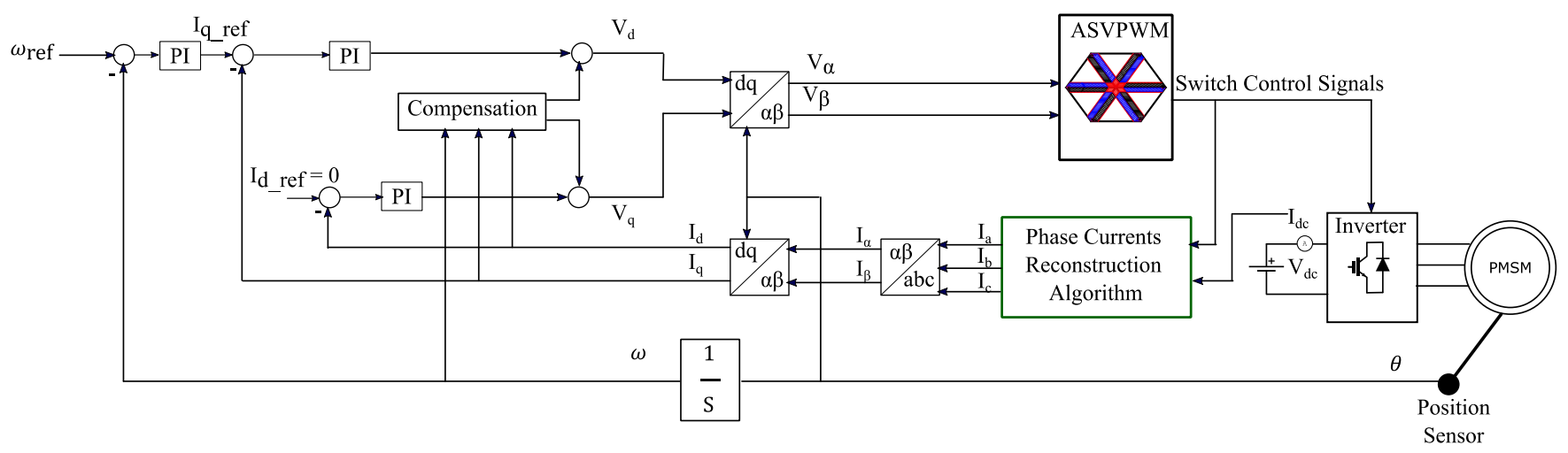

Fig. 2. Overview of the control system with DC Bus current

A state variable $S_{i}(i \in\{a, b, c\})$ represents the upper switch states. Using $\mathrm{S}_{\mathrm{i}}=1$ to represent the closed state of the upper switch of the phase "i". Conversely, $S_{i}=0$. To represent the open state.

\section{SVPWM}

The SVPWM technique is employed to obtain the required output voltage in the phase side of the inverter. It provides a higher voltage to the motor with a lower harmonics distortion. A revolving reference voltage vector is provided as voltage reference instead of the three phase voltage during a carrier period $T_{c}$. This reference vector is applied to the inverter by generating a switches control signals. The eight possible switching combination for the inverter form eight basic voltage vectors $\left(\mathrm{V}_{0}-\mathrm{V}_{7}\right)$.

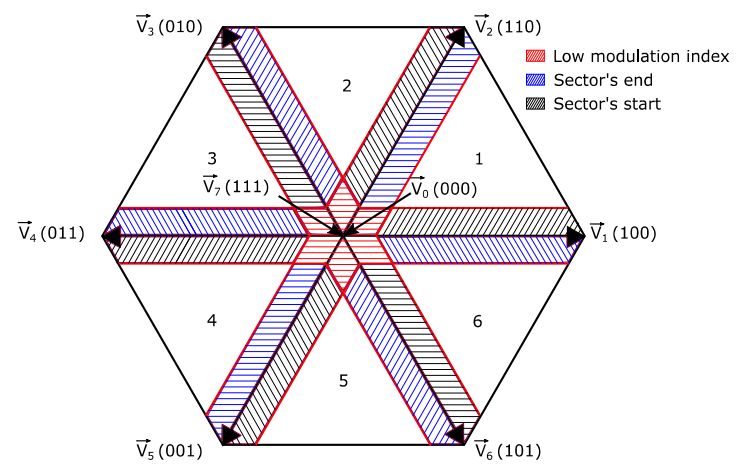

Fig. 3. Vectors and sectors of SVPWM

Six out of these eight voltage vectors producing a nonzero output voltage are known as active voltage vectors (V1-V6) and the remaining two voltage vectors producing zero output voltage are known as zero voltage vectors (V0, V7). The Six active voltage vectors shape the axes of hexagonal as depicted in Fig. 3. Meanwhile, the two zero voltage vectors are at the origin. The space between each two active voltage vectors is called sector, there are six. The angle between any adjacent two active voltage vectors is 60 degrees.

In a carrier period Tc, The SVPWM approximate the rotating reference voltage vector using the eight voltage. Depending on the placement of the reference voltage vectors, two active voltage vectors and the two zero voltage vectors contribute to the application of this reference vector. Fig. 4 shows an example of the reference voltage vector at the sector $\mathrm{n}^{\circ} 1$.

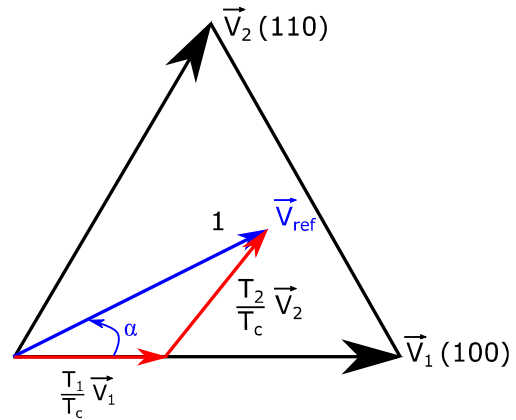

Fig. 4. Reference vector applying in sector 1

Each active voltage vector in Tc and depending on sector have a duration time of application., this duration can be calculated as follow:

$$
\left\{\begin{array}{c}
\mathrm{T}_{1}=\mathrm{T}_{c} * \frac{3 *\left|\mathrm{~V}_{\text {ref }}\right|}{2 * \mathrm{~V}_{d c}} * \frac{\sin \left(\frac{\pi}{3}-\alpha\right)}{\sin \left(\frac{\pi}{3}\right)} \\
\mathrm{T}_{2}=\mathrm{T}_{c} * \frac{3 *\left|\mathrm{~V}_{r e f}\right|}{2 * \mathrm{~V}_{d c}} * \frac{\sin (\alpha)}{\sin \left(\frac{\pi}{3}\right)} \\
\mathrm{T}_{0}=\mathrm{T}_{c}-\mathrm{T}_{1}-\mathrm{T}_{2}
\end{array}\right.
$$

Where:

$\mathrm{T}_{1}$ : application's duration of the first voltage active in each sector,

$\mathrm{T}_{2}$ : application's duration of the second active voltage vector in each sector,

$\mathrm{T}_{0}$ : application's duration of zero voltage vector in each sector.

\section{Principle of Single CURRENT SENSOR}

The use of a single current sensor requires an algorithm for reconstruction the phase's currents needed to control the PMSM. This algorithm will be essentially based on the single measure of the DC Bus current. Indeed, the idea is to assign the instantaneous measure of DC current to a phase current depending on the different states of the inverter switches. The relation between the DC Bus current and the control signals of the switches is defined as follow:

$$
\mathrm{I}_{\mathrm{dc}}=\mathrm{S}_{\mathrm{a}} * \mathrm{I}_{\mathrm{a}}+\mathrm{S}_{\mathrm{b}} * \mathrm{I}_{\mathrm{b}}+\mathrm{S}_{\mathrm{c}} * \mathrm{I}_{\mathrm{c}}
$$

The following table summarizes the relation between the DC Bus current and the phase current for each combination of the switch control signals. 
table I. Relation Between The Phase Currents And The DC Bus CuRRENT ACCORDING TO THE VOLTAGE VECTORS

\begin{tabular}{|c|c|c|c|c|c|c|c|c|}
\hline $\begin{array}{c}\text { Voltage } \\
\text { Space vector }\end{array}$ & $\mathrm{V}_{0}$ & $\mathrm{~V}_{1}$ & $\mathrm{~V}_{2}$ & $\mathrm{~V}_{3}$ & $\mathrm{~V}_{4}$ & $\mathrm{~V}_{5}$ & $\mathrm{~V}_{6}$ & $\mathrm{~V}_{7}$ \\
\hline $\begin{array}{c}\text { Dc Bus } \\
\text { current }\end{array}$ & 0 & $\mathrm{I}_{\mathrm{a}}$ & $-\mathrm{I}_{\mathrm{c}}$ & $\mathrm{I}_{\mathrm{b}}$ & $-\mathrm{I}_{\mathrm{a}}$ & $\mathrm{I}_{\mathrm{c}}$ & $-\mathrm{I}_{\mathrm{b}}$ & 0 \\
\hline
\end{tabular}

The phase currents are reconstructed in each carrier period. During this period, the reference vector applied with SVPWM is represented by two active voltage vectors and two zero voltage vectors $\left(\mathrm{V}_{0}\right.$ and $\left.\mathrm{V}_{7}\right)$. Knowing that the measurement of the Dc Bus current is done during the application of the active voltage vector, the reconstruction of two phase current is possible. The third phase current will be calculated knowing that the sum of the phase current balance system is zero.

$$
\mathrm{I}_{\mathrm{a}}+\mathrm{I}_{\mathrm{b}}+\mathrm{I}_{\mathrm{c}}=0
$$

In order to illustrate the principle of the reconstruction, we consider the case where the reference vector is located in the sector $n^{\circ} 1$. This sector is confined between two active voltage vectors: $\mathrm{V}_{1}\left(\mathrm{~S}_{\mathrm{a}}=1, \mathrm{~S}_{\mathrm{b}}=0, \mathrm{~S}_{\mathrm{c}}=0\right)$ and $\mathrm{V}_{2}\left(\mathrm{~S}_{\mathrm{a}}=1, \mathrm{~S}_{\mathrm{b}}=1, \mathrm{~S}_{\mathrm{c}}=0\right)$. The execution of the reference vector is done by applying two active voltage vectors and two zero voltage vectors during a carrier period. In order to generate the control signals to the inverter switches, these voltage vectors are applied in the following order $\mathrm{V}_{0^{-}}-\mathrm{V}_{1}-\mathrm{V}_{2}-\mathrm{V}_{7}-\mathrm{V}_{7}-\mathrm{V}_{2}-\mathrm{V}_{1^{-}}-\mathrm{V}_{0}$ as shown in the Fig. 5. Regarding the fact that the distribution of voltage vectors is symmetrical during a period, we can consider just the first half-period $\mathrm{V}_{0}-\mathrm{V}_{1}-\mathrm{V}_{2}-\mathrm{V}_{7}$

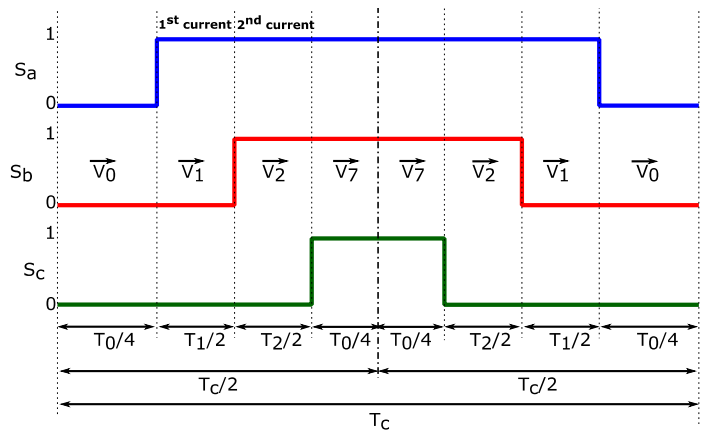

Fig. 5. Distribution of the voltage vectors in the sector $n^{\circ} 1$

The application of these voltage vectors on the inverter is shown in the "Fig. 6". Start with the zero voltage vector V0 $\left(\begin{array}{lll}0 & 0 & 0\end{array}\right)$, all the high switches of the inverter are open. In this case, the source doesn't supply power. The value of the Dc Bus current is zero $\left(I_{d c}=0\right)$. The second applied voltage vector is V1 (1 00$)$, the high switch of the phase "a" is the only one closed. In this case, the entire Dc Bus current flows through phase a $\left(I_{d c}=I_{a}\right)$. The next voltage vector is V2 ( 11 $0)$, the high switches of the phase "a" and "b" are closed. The Dc Bus current flows through two phases, so the information on the phase currents is not accurate. However, the return of the Dc Bus current flows just through the phase "c". In this case, the Dc Bus current is assigned to the phase $\mathrm{c}$ but with a negative sign $\left(I_{d c}=-I_{c}\right)$. Once two phase currents are known by the measurement of the Dc Bus current, the third current will be calculated from their values. In this case, the missing phase current is the phase $b$, its value is calculated as follow:

$$
\mathrm{I}_{\mathrm{b}}=-\mathrm{I}_{\mathrm{a}}-\mathrm{I}_{\mathrm{c}}
$$

The TABLE. III summarizes the reconstruction of the phase currents in each sector.

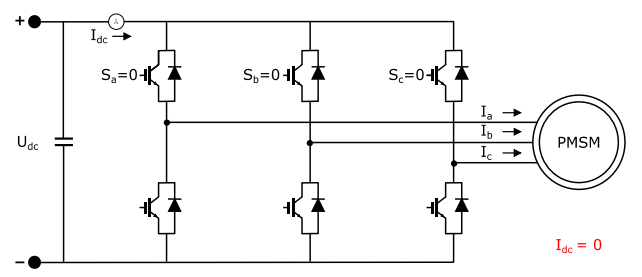

(a)

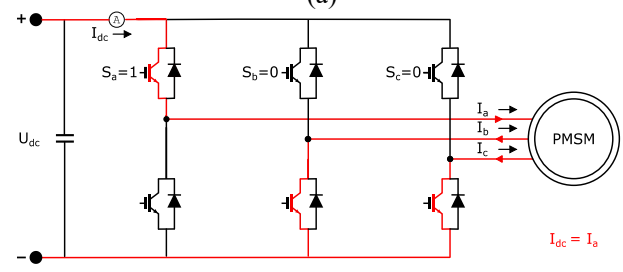

(b)

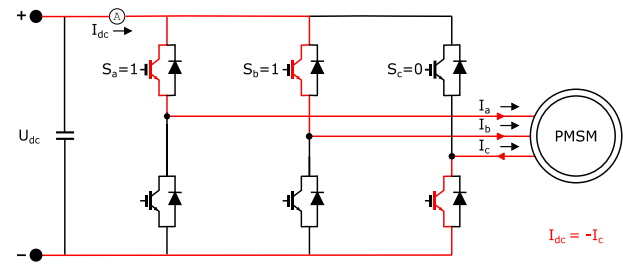

(c)

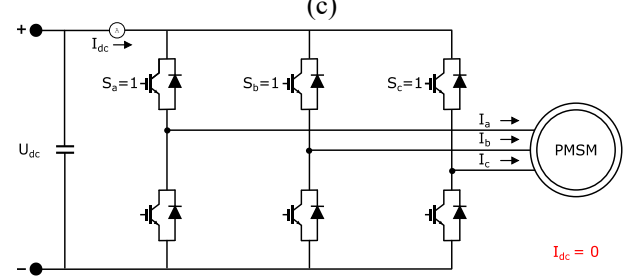

(d)

Fig. 6. Current under different voltage vectors applying in sector 1: (a) $V_{0}$ applied, (b) $V_{1}$ applied, (c) $V_{2}$ applied, (d) $V_{7}$ applied.

TABLE II. SUMMARY OF THE PHASE CURRENTS RECONSTRUCTION

\begin{tabular}{|c|c|c|c|}
\hline Sector & $\begin{array}{l}\text { Voltage } \\
\text { vector }\end{array}$ & $\begin{array}{c}\text { Measured } \\
\text { current }\end{array}$ & $\begin{array}{c}\text { Calculated } \\
\text { current }\end{array}$ \\
\hline 1 & $\begin{array}{l}\mathrm{V}_{1}\left(\begin{array}{lll}1 & 0 & 0\end{array}\right) \\
V_{2}\left(\begin{array}{llll}1 & 1 & 0\end{array}\right)\end{array}$ & $\begin{array}{l}\mathrm{I}_{\mathrm{a}} \\
\mathrm{I}_{\mathrm{c}}\end{array}$ & $\mathrm{I}_{\mathrm{b}}$ \\
\hline 2 & $\begin{array}{l}\mathrm{V}_{2}\left(\begin{array}{lll}1 & 1 & 0\end{array}\right) \\
\mathrm{V}_{3}\left(\begin{array}{llll}0 & 1 & 0\end{array}\right)\end{array}$ & $\begin{array}{l}\mathrm{I}_{\mathrm{c}} \\
\mathrm{I}_{\mathrm{b}}\end{array}$ & $I_{a}$ \\
\hline 3 & $\begin{array}{l}\mathrm{V}_{3}\left(\begin{array}{lll}0 & 1 & 0\end{array}\right) \\
\mathrm{V}_{4}\left(\begin{array}{llll}0 & 1 & 1\end{array}\right)\end{array}$ & $\begin{array}{l}\mathrm{I}_{\mathrm{b}} \\
\mathrm{I}_{\mathrm{a}}\end{array}$ & $I_{c}$ \\
\hline 4 & $\begin{array}{l}\mathrm{V}_{4}\left(\begin{array}{lll}0 & 1 & 1\end{array}\right) \\
\mathrm{V}_{5}\left(\begin{array}{llll}0 & 0 & 1\end{array}\right)\end{array}$ & $\begin{array}{l}\mathrm{I}_{\mathrm{a}} \\
\mathrm{I}_{\mathrm{c}}\end{array}$ & $I_{b}$ \\
\hline 5 & $\begin{array}{l}\mathrm{V}_{5}\left(\begin{array}{lll}0 & 0 & 1\end{array}\right) \\
\mathrm{V}_{6}\left(\begin{array}{llll}1 & 0 & 1\end{array}\right)\end{array}$ & $\begin{array}{l}\mathrm{I}_{\mathrm{c}} \\
\mathrm{I}_{\mathrm{b}}\end{array}$ & $\mathrm{I}_{\mathrm{a}}$ \\
\hline 6 & $\begin{array}{l}\mathrm{V}_{6}\left(\begin{array}{lll}1 & 0 & 1\end{array}\right) \\
\mathrm{V}_{1}\left(\begin{array}{llll}1 & 0 & 0\end{array}\right)\end{array}$ & $\begin{array}{l}\mathrm{I}_{\mathrm{b}} \\
\mathrm{I}_{\mathrm{a}}\end{array}$ & $\mathrm{I}_{\mathrm{c}}$ \\
\hline
\end{tabular}
ALGORITHM

\section{ENHACED PHASE CURRENT RECONSTRUCTION}

The reconstruction algorithm is based on the measurement of Dc bus current, this measurement is done during the application of the active voltages. The measured value will be process and assign to the right phase.

In practice, the current measurement process requires a certain amount of time to be completed. This time is equal to the sum of the dead time of the inverter $T_{\text {dead, }}$, the time of establishment current $T_{\text {set }}$ and the digital analogic conversion 
time $T_{\text {adc }}$. In the rest of the paper, we call $T_{\text {mina }}$ the minimum duration of current acquisition and it is defined as follow:

$$
\mathrm{T}_{\text {mina }}=\mathrm{T}_{\text {dead }}+\mathrm{T}_{\text {set }}+\mathrm{T}_{\mathrm{adc}}
$$

To have a proper reconstruction of the phase currents, the duration of the application of the active vector should be greater than the minimum time of the current acquisition.

The measurement process requires the continuity of the current for a certain time which has been called the minimum duration of current acquisition. In our application, the measurement of the DC Bus current is made during the application of the active voltage vectors. These have a definite duration time of application in each carrier period.

In the Fig. 3, hatched areas represent the different values of the reference voltage vector where the phase current reconstruction is not possible. Indeed, the generation of the reference vector in these areas is done via the application of two active voltage vector where their application times are less than the minimum duration of current acquisition "Tmina".

In order to ensure the continuity of the current measurement process in the hatched zones, the solution is to extend the duration time of application of the active voltage vector to reach a duration time higher than $\mathrm{T}_{\text {mina }}$. The principle is based on the replacement of the original reference vector, during a carrier period, by two new reference vectors. Each reference vector will be applied for a half-carrier period:

- $\mathrm{V}_{\text {mes}}$ : The first reference vector applied during the first half-carrier period, called the measurement reference vector $\mathrm{V}_{\text {mes. }}$. The two current acquisitions are made during this period

$-\mathrm{V}_{\text {comp }}$ The second vector called the compensation reference vector $\mathrm{V}_{\text {comp. }}$. The application of this vector allows to compensate the effect of the duration extension done by the Vmes to keep the mean value of the two new reference vectors equal to that of the original reference vector during a carrier period.

The hatched areas shown in Fig. 3 are divided, according to the position of the reference vector in the hexagon, into three parts:

\section{A. Sector's start}

In this zone the measurement of the phase current provided by the application of the second active voltage vector V2 (110) is not possible, because its application time $T_{2}$ is less than the minimum duration of current acquisition $T_{\text {mina }}$ Actually, the angle of the reference vector is of low value which causes a short application time of the second active voltage vector.

In order to fix this and as example, we replace the reference vector " $V_{\text {ref }}$ " by two new reference vectors as shown in Fig. 7.The measurement reference vector "Vmes" provides the necessary magnitude and angle to extend the duration time $T_{2}$ up to $T_{\text {mina }}$ as illustrated in Fig. 8. This new reference vector will be in the same sector " 1 " as the base reference vector, while the compensation reference vector " $\mathrm{V}_{\text {comp }}$ " will be in the adjacent sector " 6 ". The magnitude and the angle of the compensation reference voltage vector are calculated in such a way as to keep the mean value of the two new reference vectors equal to that of the basic reference vector.

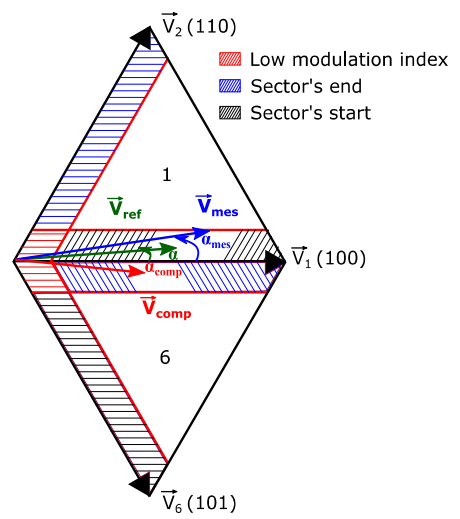

Fig. 7. Reference vector applying at the beginning of sector 1

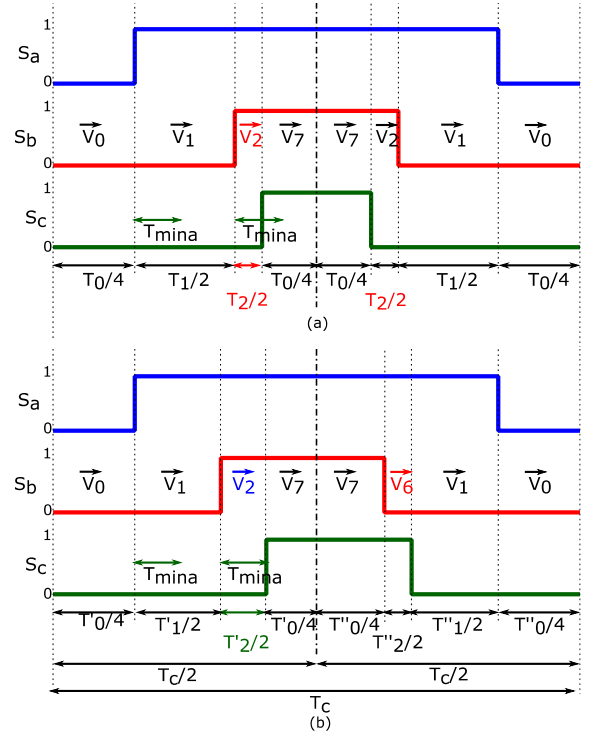

Fig. 8. Switching control signal applying at the start of sector 1: (a) with Standard SVPWM, (b) With Adjusted SVPWM

\section{B. Sector's end}

In this area, the measurement of the current provided by the application of the first active voltage vector is not possible, because its application time $T_{1}$ is less than the minimum duration of current acquisition $T_{\text {mina. }}$. Actually, the value of the reference vector angle is close to $\pi / 3$ which causes a short duration of application of the second active voltage vector.

In order to fix this, we will apply the same method as the case of the beginning of sector. But in this one, the magnitude and angle of the reference vector will be calculated to extend the duration time $\mathrm{T}_{1}$ to the value of $\mathrm{T}_{\text {mina }}$ as depicted in Fig. 10 . The compensation reference vector will be, this time, in the adjacent sector $\mathrm{n}^{\circ} 5$ as shown in the Fig. 9.

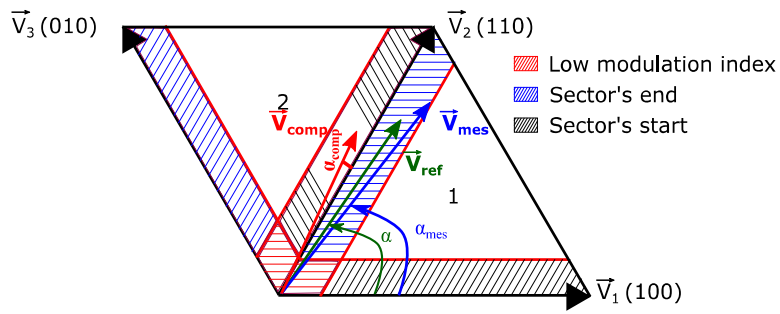

Fig. 9. Reference vector applying at the end of sector 1 


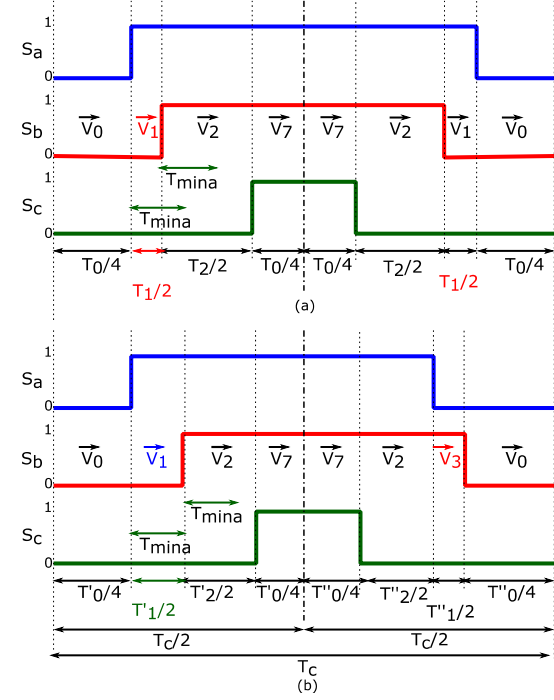

Fig.10. Switching control signal applying at the end of sector 1: (a) with Standard SVPWM, (b) With Adjusted SVPWM

\section{Low modulation index}

In this case the problem is more complicated, the measurement of the current provided by the application of the two active voltage vectors is not possible. This is due to the low value of the reference vector magnitude as depicted in Fig. 11, which generates a short duration time of application of the active voltage vectors T1 and T2 as shown in Fig. 12. These duration time are both less than the minimum duration of current acquisition $\mathrm{T}_{\text {mina. }}$.

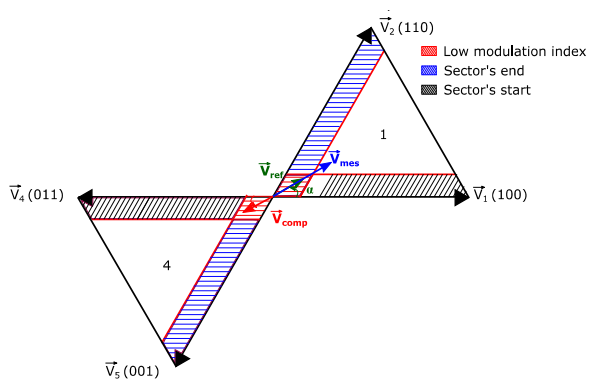

Fig. 11. Reference vector with a low modulation index applying in sector 1

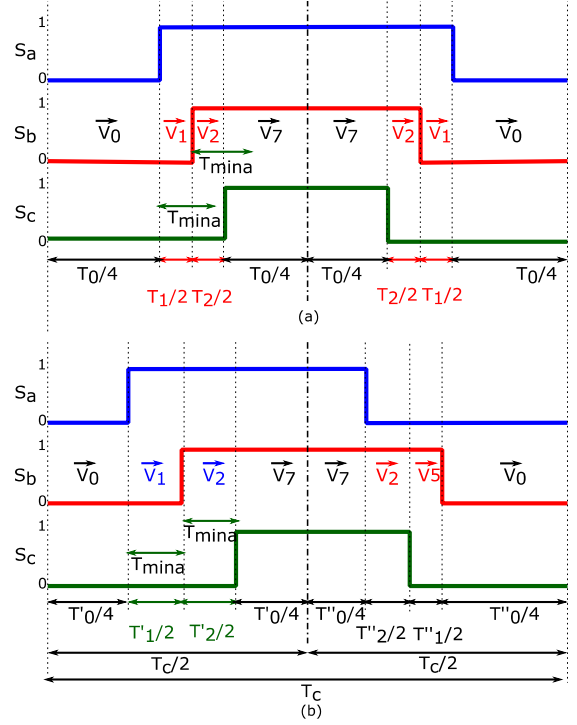

Fig. 12. Switching control signal for a reference vector with a low modulation index applying in sector 1: (a) with Standard SVPWM, (b) With Adjusted SVPWM
To resolve this problem, we replace the reference vector by two new reference vectors as illustrated in Fig. 11. The measurement vector has the same angle as the basic reference vector but with a larger module to ensure a duration time of application of the two active voltage vectors T1 and T2 equal to the Tmina as shown in Fig. 12 This measurement vector is in the same sector as that basic reference vector "1", while the compensation vector will be in the opposite sector " 4 " as shown in Fig. 11.

\section{SimUlation AND ANALYSIS}

In order to validate the phase current reconstruction algorithm proposed above at high speed, a simulation of the speed control of the permanent magnet synchronous machine is carried out with the Adjusted SVPWM in Matlab/Simulink.

The designed control system is represented in Fig. 2 The simulation parameters are set as follow: PMSM rated speed $5000 \mathrm{rpm}$, pole pairs 5, DC Bus voltage $320 \mathrm{~V}$, rated Power $5 \mathrm{~kW}$, rated torque $5 \mathrm{Nm}$. This parameters refer to a real PMSM for an air-conditioner application.

Fig. 13.a shows the results of simulation of the speed variation which varies from 0 to $9000 \mathrm{rpm}$ with a step at 5000 rpm. And Fig. 13.b represents the reconstructed phase currents. The switching and a sampling frequency set at 10 $\mathrm{kHz}$.

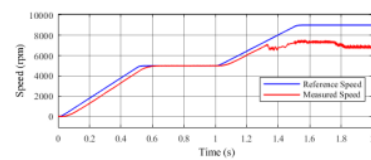

(a)

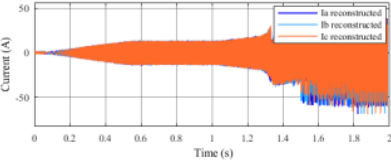

(b)
Fig. 13 : (a) PMSM speed with $\mathrm{f}_{\mathrm{sw}}=10 \mathrm{kHz}$, (b) reconstructed phase current

We notice a good follow-up of the measurement speed until $5000 \mathrm{rpm}$ with some delay due to the speed controller parameters. Above this limit, we observe an underperformance of the control. This is due to the loss of the phase currents reconstruction, because from $5000 \mathrm{rpm}$ the acquisition points are not enough for the reconstruction.

A solution to overcome this problem is to modify the switching frequency. In Fig. 14 we restart the same simulation with a switching and a sampling frequency set at $20 \mathrm{kHz}$.

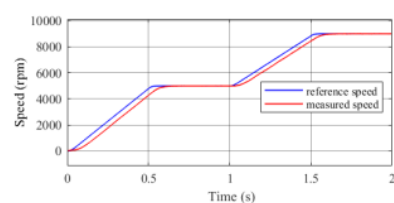

(a)

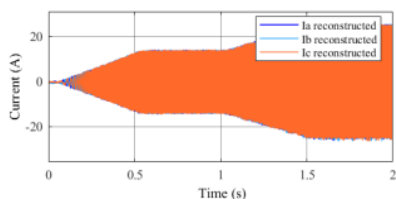

(b)
Fig. 14. (a) PMSM speed with $\mathrm{f}_{\mathrm{sw}}=20 \mathrm{kHz}$, (b) reconstructed phase currents

In this case, the speed ripples are eliminated as shown in Fig. 14a. The corresponding current at $5000 \mathrm{rpm}$ and 9000 rpm are depicted in Fig. 14b. We notice that with switching frequency set at $20 \mathrm{kHz}$, the phase currents are reconstructed at $9000 \mathrm{rpm}$ as well as at $5000 \mathrm{rpm}$.

In The Fig 15, a zoom on the reconstructed phase currents and the phase currents obtained via simulation at $5000 \mathrm{rpm}$ and at $9000 \mathrm{rpm}$ with ASVPWM is presented. 


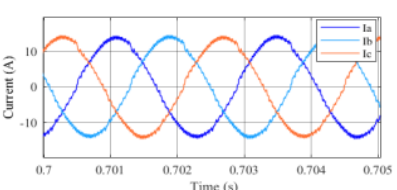

(a)

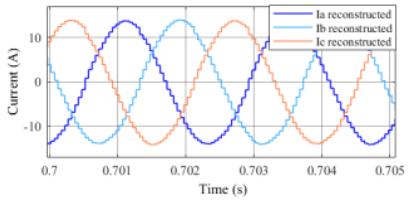

(c)

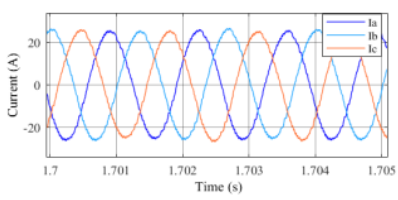

(b)

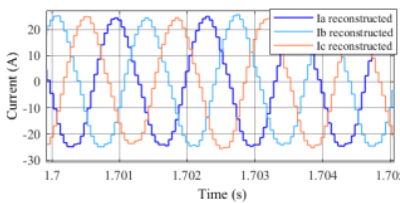

(d)
Fig. 15. Phase currents: (a) current obtained via simulation at $5000 \mathrm{rpm}$, (b) currents obtained via simulation at $9000 \mathrm{rpm}$ (c) Reconstructed current at $5000 \mathrm{rpm}$, (d) reconstructed current at $9000 \mathrm{rpm}$

On one hand, we can notice that the phase current are not deteriorated with the modification of the SVPWM at 5000 $\mathrm{rpm}$ or $9000 \mathrm{rpm}$. On the other hand, the phase currents are properly reconstructed. The Fig 17 presents a comparison of the reconstructed current and the current obtained by simulation of the phase a.

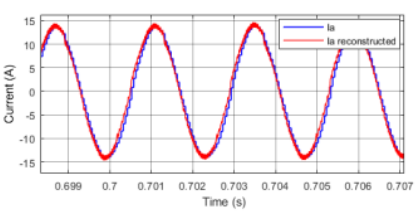

(a)

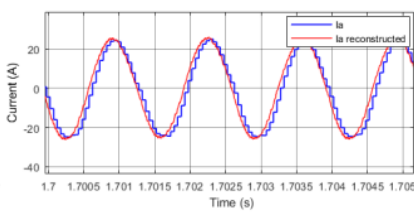

(b)
Fig. 16. Comparison between reconstructed current and the current obtained via simulation of the phase a: (a) at $5000 \mathrm{rpm}$, (b) at $9000 \mathrm{rpm}$

The Fig. 16. shows a good concordance between the two currents at low speed as high speed, witch confirms the good reconstruction of the phase currents in the different operating points.

Fig. 17. shows the spectrum of reconstructed phase current and the spectrum of the phase current obtained via simulation at $5000 \mathrm{rpm}$.

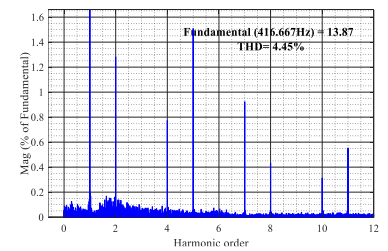

(a)

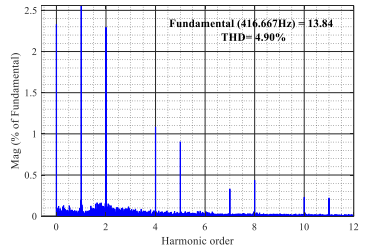

(b)
Figure 17 : (a) spectrum of phase currents obtained via simulation at 5000 rpm, (b) spectrum of reconstructed phase currents at $5000 \mathrm{rpm}$

The THD is $4,45 \%$ of the phase current obtained via simulation, whereas the THD of the reconstructed phase current is $4.90 \%$. So, the distortion in waveforms of the reconstructed phase current is quite low.

\section{CONCLUSION}

In this paper, a PMSM control technique with a single current sensor is proposed. A phase currents reconstruction algorithm was developed. This latter presents some limits due to the dead zone induced by the SVPWM. An Adjusted SVPWM was presented in order to overcome these issues. A simulation test was carried out to validate the reliability of the algorithm at a high speed with different switching frequency.

We have highlighted that speed ripples appear at high speed, due to the low switching and carrier periods. Indeed, the number of the current acquisition points were not enough to properly reconstruct the phase currents. We can conclude that the principal limitation of the high speed control is the carrier period.

Future work aims at experimental implementation and validation of the developed algorithm on an experimental test bench available at the Lab.

\section{REFERENCES}

[1] X. Liu, H. Chen, J. Zhao, and A. Belahcen, "Research on the performances and parameters of interior PMSM used for electric vehicles," IEEE Trans. Ind. Electron., vol. 63, no. 6, pp. 3533-3545, Jun 2016.

[2] M. Pinilla and S. Martinez, "Selection of main design variables for lowspeedpermanent magnet machines devoted to renewable energy conversion," IEEE Trans. EnergyConvers., vol. 26, no. 3, pp. 940-945, Sep. 2011.

[3] F. Niu, B. Wang, A. S. Babel, K. Li, and E. G. Strangas, "Comparative evaluation of direct torque control strategies for permanent magnet synchronous machines," IEEE Trans. Power Electron., vol. 31, no. 2, pp. 1408-1424, Feb 2016.

[4] T. M. Wolbank, P. E. Macheiner, "Current-Controller With Single DC Link Current Measurement for Inverter-Fed AC Machines Based on an Improved Observer-Structures," IEEE Trans. Pow.Electronc, vol.19, no. 6, Nov 2004.

[5] Woo-Cheol Lee, "Comparison of Single-Sensor Current Control in the DC Link for Three-Phase Voltage-Source PWM Converters",IEEE Transactions on Industrial Electronics, Vol. 48, No.3, pp.491-505, June, 2001.

[6] Y. GU, F. NI, D. yang, and H. Liu, " A Novel Phase Current Reconstruction Method Using a Single DC-Link Current Sensor", no. 2006, pp. 4878-4879, 2009.

[7] J-H. Im, R-Y. kim "Improved Saliency-based Position Sensorless Control of Interior Permanent -magnet Synchronous Machines with Single DC-Link Current Sensor Using Current Prediciton Method," IEEE Trans. Ind. Electron, vol. 0046, no. c, pp. 1-1, 2017.

[8] B. Saritha, P-A. Janajiraman, "Sinusoidal three-phase current reconstruction and control using a DC-link current sensor and a curvefitttins observer," IEEE Trans. Ind. Electron., vol. 54, no. 5, pp. 2657 2664, 2007

[9] A. kraemer, V. Heusinger, S. Schad, and A. Ali, " Sensorless Vector Control of PMSM with Observer-Based Phase Current Reconstruction using only DC-Link Current Sensor.” Pp.145-150,2017.

[10] X. F. Blaabjerg, J. K. pedersen, "An Ideal PWM-VSI Inverter Using Only Once Current Sensor In The Dc-Link", power Electonics and variable-Speed Drives, pp. 458-464, Oct, 1994.

[11] S. C. Yang, G. R. Chen, "AC Voltage and Current Sensorless Control of Three-Phase PWM rectifiers", IEEE Trans. Power Electron., vol. 17, no. 6 , pp. 883-890, Nov. 2002

[12] K. Hongrae, M. J. Thomas, "Current control for ac motor drives using a single de-link current sensor and measurement voltage vectors," IEEE Trans on Industry Applications, vol. 42, no. 6, pp. 1539-1547, Nov. 2006.

[13] H. Kim and T. M. Jahns, "Current control for AC motor drives using a single DC link current sensor and measurement voltage vectors," IEEE Trans. Ind. Appl., vol. 42, no. 6, pp. 1539-1547, Nov./Dec. 2006. 